\title{
Overturning of the façade in single-nave churches under seismic loading
}

\author{
Gianmarco de Felice $^{1}$ (D) $\cdot$ Rebecca Fugger $^{1}$ (D) Francesca Gobbin $^{1}$ (D)
}

Received: 29 March 2021 / Accepted: 25 September 2021 / Published online: 8 November 2021 (C) The Author(s) 2021

\begin{abstract}
The out-of-plane collapse of the façade represents one of the major threats and the most frequent cause of damages of churches due to strong earthquakes. Due to the slenderness of the façade and the lack of adequate connections to the side walls and the wooden roof, the seismic action can trigger the overturning. A detailed assessment is therefore required to judge whether or not to intervene. This paper presents an approach for the seismic assessment of the stability of the façade, through a discrete element model based on a photographic survey, with the aim of representing the actual geometry and arrangement of the stone units and their effects on the kinematics of the overturning. The collapse mechanism is simulated with both, quasi-static pushover and dynamic pulse-based analyses and the results compared to those of conventional rigid-body kinematics. The proposed approach is then applied to seven masonry churches that suffered severe damages during the 2009 L'Aquila (Italy) earthquake and the failure mode provided by the analyses is compared to the damages caused by the earthquake. The method is able to give a reliable estimate of the expected failure mechanism, taking into account the quality of the masonry and the connections to the side walls, while also providing the seismic acceleration required to trigger the motion and the ultimate displacement beyond which collapse occurs.
\end{abstract}

Keywords Masonry $\cdot$ Discrete element method $\cdot$ Church $\cdot$ Overturning $\cdot$ Pushover analysis

\section{Introduction}

Masonry churches are not designed to withstand horizontal loads and their vulnerability is considerably higher than that of ordinary masonry buildings. This conjecture is confirmed by the damage that has occurred during the seismic events that have struck Italy in the recent decades (Doglioni, F, Moretti, A, and Petrini 1994; Da Porto et al. 2012; Sorrentino et al. 2014; De Matteis et al. 2019; Penna et al. 2019). Because of their structural morphology, characterised by a prevailing longitudinal dimension, slender perimeter walls and the lack of internal diaphragms, churches rarely show a global response to seismic action, but rather a local response in which the most vulnerable structural elements detach from the

Francesca Gobbin

francesca.gobbin@uniroma3.it

1 Department of Engineering, Roma Tre University, Via vito volterra 62, 00146 Rome, Italy 
rest and collapse with a rigid body motion (Lagomarsino and Podestà 2004a, b). Accordingly, the seismic behaviour of these buildings is often analysed by considering each architectural component (façade, apse, bell-tower, dome, vault, triumphal arche, etc.), named macro-element, which is characterized by a substantially autonomous structural response. For instance, the Italian guideline for monumental buildings (MiBACT 2015) suggests considering twenty-eight collapse mechanisms determined a priori. The verification of each collapse mechanism can be carried out on the basis of the kinematic theorem of limit analysis (Heyman 1966), which provides the capacity curve, and through the identification of an equivalent oscillator to estimate the corresponding seismic demand. Alternatively, the seismic demand can be estimated according to the rocking model (Housner 1963), and the different mechanisms analysed through linearization of the equation of motion, considering pulse-type ground motion (Mauro et al. 2015).

However, the construction details and quality of the masonry significantly influence the collapse mechanism and the adoption of a predefined shape of the macro-element is not always straightforward (Milani and Valente 2015a). For example, the detachment of façades is generally studied through simplified models based on the assumption that the façade behaves like a rigid body, detaching with a vertical crack from the transverse wall. However, this approach hardly predicts the actual behaviour that occurs during seismic action with regard to both, the part undergoing rocking motion and the position of the hinges (Milani and Venturini 2011). The shape and position of the cornerstones that provide the interlock between the façade and the transverse walls, in particular, plays a fundamental role in the structural response in the event of seismic action (de Felice and Mauro 2010).

A refined method to predict the out-of-plane behaviour of façades of the churches is particularly relevant, considering that during the earthquake that struck L'Aquila in 2009, the collapse of façades was the prevailing cause of damage of religious architectural heritage. The survey of damages reported that in a stock of 241 churches, $30 \%$ of the sample was damaged due to the activation of façade first-way collapse mechanism (Da Porto et al. 2012). A similar behaviour was also noted during the seismic events in central Italy in 2016, where the overturning of the façades was one of the recurring damage caused by the lack of efficient connections to the longitudinal walls. (Penna et al. 2019). Therefore, it becomes necessary to resort to a refined model that allows to study the collapse mechanism of the façade in masonry churches, by modelling the construction details that affect the structural behaviour. Various numerical methods have been proposed in these years (Casolo 2000; Milani et al. 2013; Milani and Valente 2015b; Pantò et al. 2017, 2016; Asteris et al. 2017; Casapulla et al. 2017; de Felice et al. 2017; Iannuzzo 2019; Lasciarrea et al. 2019; Malena et al. 2019). However, the effective masonry pattern is not taken into consideration in any of these methods.

The present work aims at proposing a new approach to assess the out-of-plane collapse mechanism of masonry buildings, based on a refined modelling of masonry walls with distinct elements (Lemos 2007; de Felice 2011) with the aim of representing the actual geometry and arrangement of the stone units and their effects on the kinematics of the local mechanism. Thanks to the careful reproduction of masonry pattern and to the capability of the DEM in simulating the motion in finite kinematics, the collapse mechanism and the crack pattern induced by the seismic action are detected, without the need to define the mechanism a priori. The effectiveness of the Discrete Element Method (DEM) to capture the seismic behaviour of masonry structures has already been proved in Literature (Azevedo et al. 2000; de Felice 2011; Al Shawa et al. 2012; Malomo et al. 2018; Mordanova and de Felice 2018; Meriggi et al. 2019) but its use for seismic assessment still 
needs to be settled. Accordingly, a procedure for static pushover and dynamic impulsive analyses has been developed in (Gobbin et al. 2021) and applied here to seven masonry churches located in L'Aquila (Italy) region and damaged during the 2009 earthquake. For each church, the connection of the façade to side walls is discretized into $2 \mathrm{D}$ distinct elements and the out-of-plane failure of the façade is modelled with either static or dynamic analyses to provide respectively, the capacity curve and the overturning domain. The comparison between the model predictions and either the earthquake damage or the analytical expressions for the rigid block, allows to assess both the reliability of the proposed approach and the limitation of the conventional rigid-body kinematics.

\section{The conventional rigid-body analysis}

As a reference for the following numerical analyses, let us consider the façade simply as a parallelepiped rigid body having thickness $b_{f}$, height $h_{f}$, semi-diagonal $R$, weight $W$, slenderness angle $\alpha=\frac{b_{f}}{h_{f}}$ (Fig. 1), and denote by $\theta$ the tilting of the façade towards the outside.

The horizontal seismic acceleration $\widehat{a}_{0}^{s t}$ that trigger the overturning mechanism and the horizontal displacement of the centre of gravity $\widehat{d}_{0}^{s t}$ beyond which the façade collapses are respectively:

$$
\hat{a}_{0}^{s t}=g \alpha ; \hat{d}_{0}^{s t}=\frac{b_{f}}{2}
$$

Accordingly, the capacity curve for slender walls is simply a bilinear curve with a first rigid branch up to the maximum acceleration $\widehat{a}_{0}^{s t}$ and a decreasing linear branch up to the maximum displacement $\widehat{d}_{0}^{s t}$ (Fig. 2).

In the case of dynamic loading, as shown in (Housner 1963), a well-known analytical solution is obtained for a half sinusoidal wave acceleration pulse defined as: $a(t)=-\widehat{a} \sin (\omega t+\psi)$, where $\omega$ is the circular frequency of the sinusoidal wave and $\hat{a}$ the amplitude acceleration, while $\psi=\sin ^{-1}\left(\frac{g}{\hat{a}} \sin \alpha\right)$ is a phase angle which insures that at time $t=0$ the base acceleration have reached the value $\hat{a}_{0}^{s t}$ required to initiate rocking. The equation of motion can be written as:

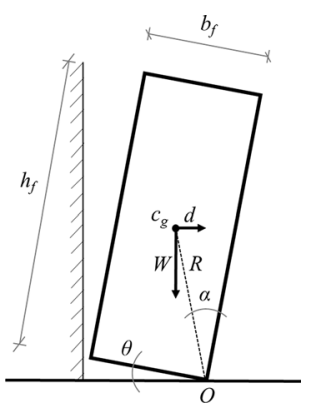

Fig. 1 Rigid body model during rocking motion 

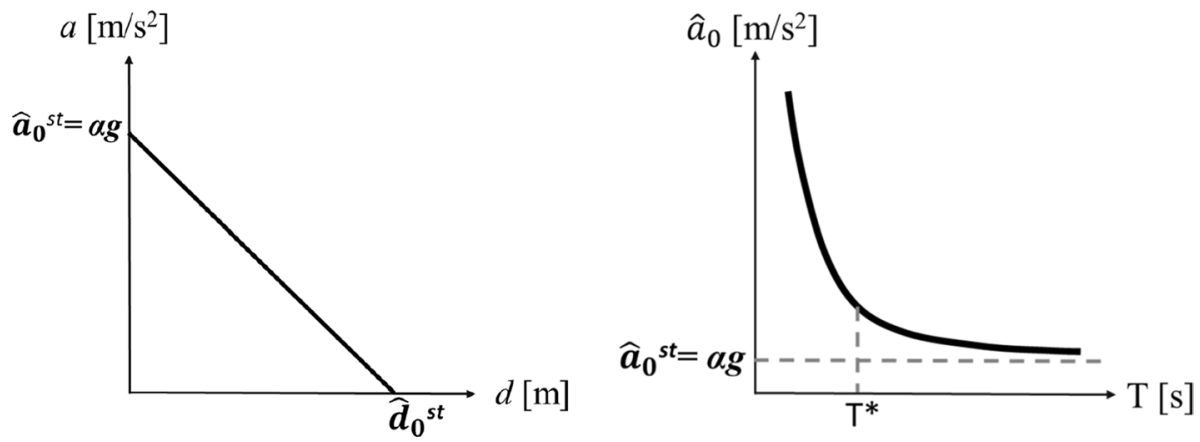

Fig. 2 Capacity curve (left) and rocking overturning domain (right) under sinusoidal pulse, provided by conventional rigid body analysis

$$
I_{o} \theta=-W R \sin (\alpha-\theta)+W R \frac{\hat{a}}{g} \sin (\omega t+\psi)
$$

where $I_{o}$ is the moment of inertia of the façade about the rotation hinge. Assuming the façade is slender $\left(\alpha<15^{\circ}\right)$ and setting $p^{2}=\frac{W R}{I_{o}}$, the equation of motion becomes:

$$
\theta-p^{2} \theta=\alpha p^{2}\left[\frac{\sin (\omega t+\psi)}{\sin \psi}-1\right]
$$

The condition for overturning can be obtained by imposing that $\theta=\alpha$ at the end of the pulse, and the resulting equation provides the amplitude $\widehat{a}_{0}$ of the sinusoidal pulse with circular frequency $\omega$ required to just overturn the façade:

$$
\hat{a}_{0}(\omega)=g \alpha \sqrt{1+\frac{I_{o}}{W R} \omega^{2}}
$$

The limit condition provided by Eq. (4) can be summarised by the rocking domain (Fig. 2), which expresses the amplitude of the pulse as a function of its period. Above the curve, the façade fails, while below it recovers. The horizontal asymptote corresponds to the acceleration $\hat{a}_{0}^{s t}$ below which the rocking motion is not activated (Mauro et al. 2015), while the period $\mathrm{T}$ "such that the tangent to the overturning domain is equal to -1 separates the long periods for which the domain is mainly controlled by the pulse acceleration from the short periods controlled by the pulse duration.

\section{The Numerical model}

\subsection{Discrete element modelling}

The proposed numerical model is based on the DEM (Cundall 1971) originally conceived for the study of rocks mechanics. The method is able to take into account the arrangement and interlocking of block units, by explicitly modelling the cracks and discontinuities that may occur during the motion and follows the displacement in finite kinematics, where single blocks can detach from the rest of the construction as the 
collapse mechanism evolves. In the present case, the blocks are considered as rigid bodies, while the contacts are modelled by a normal spring and a shear spring located at the edges of the blocks. The joint normal stiffnesses, $K_{N}$, is determined by dividing the overall elastic modulus of masonry $E_{m}$ to the average blocks height $h_{m}$. Shear stiffness, $K_{S}$, is simply considered as half of the normal stiffness (Al Shawa 2012; Meriggi 2019; Mordanova 2018). However, stiffness does not significantly affect the results in the absence of second-order effects (de Felice 2011). The height of the blocks differs from case to case and also between the façade and the side wall, from a minimum of $15 \mathrm{~cm}$, in the side wall of the church of S. Maria ad Cryptas, to $40 \mathrm{~cm}$, for the lower part of the side wall of the church of S. Stefano. The strength of the contact is controlled by a Mohr Coulomb condition $|\tau| \leq \sigma \cdot \tan (\varphi)$, assuming a friction angle $\varphi=30^{\circ}$, while neglecting cohesion and tensile strength (Meriggi 2019, Mordanova 2018). With the assumption of rigid blocks, the equations of motion are explicitly integrated through the central difference scheme only for the centroid of each block at each cycle, resulting in a lower computational burden. Once blocks velocities are derived, displacement and forces are calculated at the interfaces on the basis of the stiffnesses at the contacts. The cycle ends with the determination of blocks forces. Even though the DEM is based on a dynamic relaxation algorithm, static convergence is possible through a fictitious damping, that dissipates residual vibrations (Lemos 2012).

The DEM approach is far more time-consuming than rigid block limit analysis (Portioli 2020), but has the following main advantages: (1) the configuration is updated during the analysis in finite deformation, thus allowing the softening branch of the pushover curve to be captured; (2) the brittle behavior can be accounted for in the analysis, thus allowing to include an initial cohesion or a tensile strength that vanishes with the opening of the joint.

\subsection{Discretization of masonry}

Aiming at reproducing the effective connections with the lateral walls, each stone is modelled according to the actual geometry obtained from the survey of the wall face in a polygonal shape which incorporates the stone and the semi-thickness of the mortar joint. Such a refined model is used for the thickness of the façade and the adjacent part of the longitudinal wall, while the remaining part is modelled as an elastic block since it does not affect the collapse mechanism. A vertical fictitious joint with infinite tensile strength and cohesion, is used to join the blocks belonging to both the façade and the side wall, thus providing the interlocking between the two walls. The model is bidimensional and, accordingly, the blocks densities and contact stiffnesses are multiplied by their effective depth: either half of length of the façade $l_{f}$, or the thickness of the transverse wall $b_{s}$, as shown in Fig. 3, where the façade and the side wall heights are respectively denoted as $h_{f}$ and $h_{s}$, their thickness as $b_{f}$ and $b_{s}$. The length of the façade is denoted by $l_{f}$, while $l_{s}$ represents the length of the adjacent side wall that is explicitly modelled. If there are openings in the façade, such as doors, windows or rosettes, their extent is deducted from the calculation of the actual thickness to be considered in the definition of densities and stiffnesses. Finally, the structure is laid on a rigid block that forms the base of the model. 


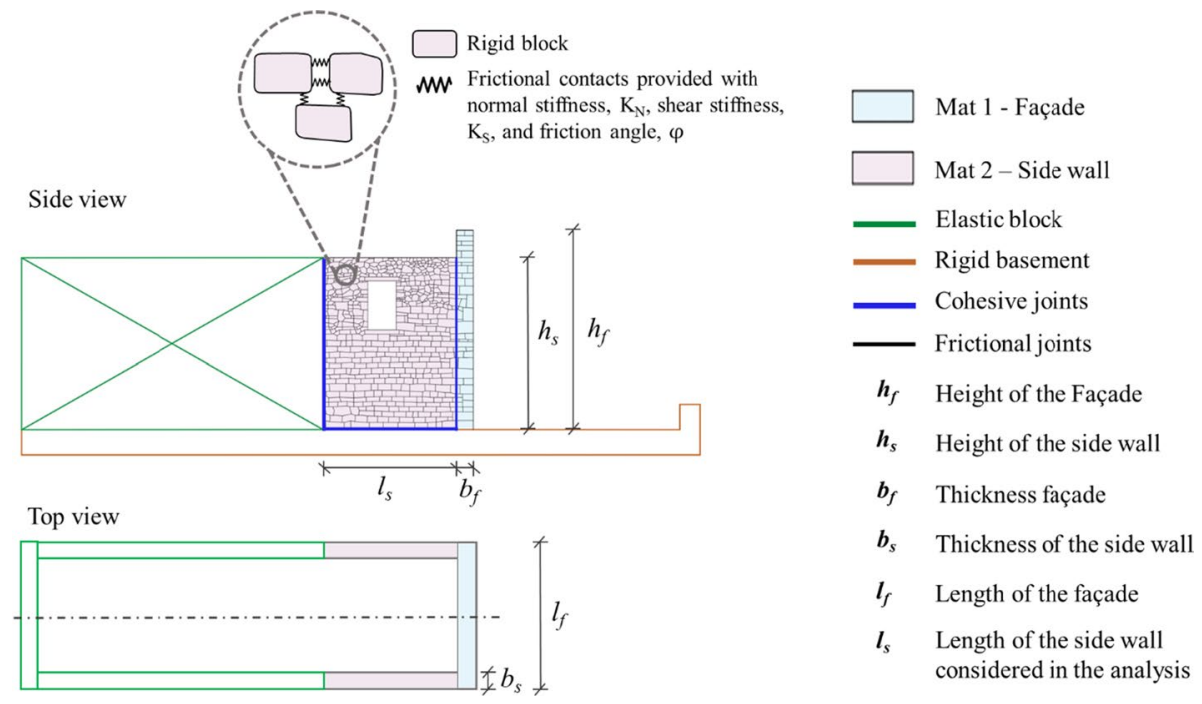

Fig. 3 Outline of the single nave church and corresponding 2D Distinct Element Model

\subsection{Pushover quasi-static analysis}

Following the procedure proposed in (Gobbin et al. 2021) the ascending branch of the pushover curve is simply obtained under force control, by applying the horizontal ground acceleration $a_{g}$ to the centroids of each block in small increments and checking for quasi-static equilibrium. The maximum acceleration $a_{0}{ }^{\text {st }}$ for which convergence is reached corresponds to the peak of the capacity curve. The acceleration steps are progressively decreased when approaching to $a_{0}{ }^{s t}$, as shown by the acceleration and displacement time-histories depicted in Figs. 4 and 5, respectively, where $t_{p}{ }^{s t}$ denotes the time at which the maximum acceleration is reached, and $d_{p}{ }^{s t}$ the corresponding displacement. A ground acceleration greater than $a_{0}{ }^{\text {st }}$ would activate the collapse mechanism.

Once the mechanism is triggered by slightly increasing the ground acceleration $a_{g}$ over the threshold $a_{0}{ }^{s t}$, the softening branch is obtained under displacement control. The effective acceleration $a_{e f f}$ of the blocks involved in the collapse mechanism is lower than the applied ground acceleration $a_{g}$, due to the non-equilibrium state, and accordingly the base shear $V$ is lower than the product of the overall mass $m$ and the ground acceleration $a_{g}$. For a given displacement of the control point, the effective acceleration can be estimated by detecting those blocks which are failing and computing the corresponding mass $m^{*}$. Then, the effective acceleration of the mechanism can be estimated as the ratio of the base shear depurated by the contribution of the portion of the structure that is not failing, and the failing mass $m^{*}$ as follows:

$$
a_{e f f}=\frac{V-a_{g}(m-m *)}{m *}
$$

The detailed procedure implemented into the discrete element code is described in (Gobbin et al. 2021). By repeating this procedure in small steps and progressively decreasing the imposed ground acceleration, the whole softening branch of the capacity 
Fig. 4 Time-histories of the horizontal acceleration applied in quasi-static pushover and pulsedynamic analyses

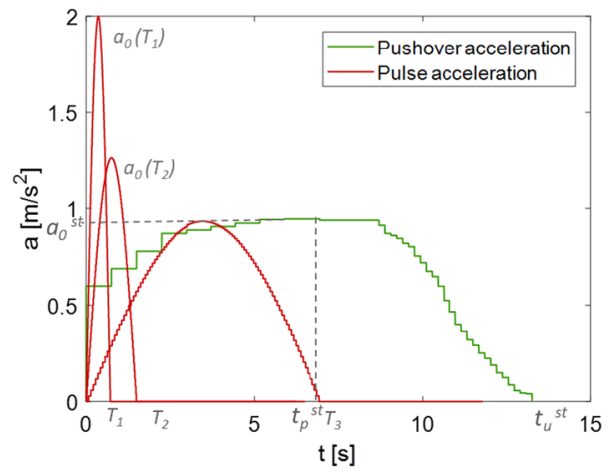

curve is obtained up to the ultimate displacement $d_{0}{ }^{\text {st }}$ corresponding to $a_{\text {eff }}=0$. The displacement capacity $d_{0}{ }^{\text {st }}$ represents the maximum allowed displacement for which the structure reaches the unstable equilibrium in the absence of horizontal acceleration. A displacement greater than $d_{0}{ }^{s t}$ would cause the overturning of the façade.

\subsection{Pulse-based dynamic analysis}

The pulse-based analysis is carried out by applying a half sinusoidal acceleration lasting for a time period $T=\pi / \omega$ with amplitude $a$ to the rigid basement in the horizontal direction and without damping:

$$
a(t)=\left\{\begin{array}{c}
-a \sin (\omega t) t \leq \pi / \omega \\
0 t>\pi / \omega
\end{array}\right.
$$

The analysis is repeated for varying amplitude and duration to detect the amplitude $a_{0}$ and period $T_{0}$ of the acceleration pulse after which the façade overturns. The failure mechanism is directly provided by the analysis and the algorithm automatically recognizes if collapse occurs or if the structure recovers: in the first case the displacement of the control point diverges, while in the second case it reaches its peak and then reduces as shown in Figure.

Two different strategies are followed based on the length of the pulse. For long pulses, having period longer than $T^{*}$, given a pulse duration $T_{0}$, the amplitude is progressively increased starting from the value $a_{0}{ }^{\text {st }}$ up to the value $a_{0}\left(T_{0}\right)$ after which collapse takes place. For very long pulses, the dynamic analysis provides the same acceleration $a_{0}{ }^{\text {st }}$ given by pushover, while an acceleration lower than $a_{0}{ }^{\text {st }}$ would not activate the motion. Conversely, for short pulses, given an acceleration amplitude $a_{0}$, the period is progressively increased up to the value $T_{0}\left(a_{0}\right)$ after which collapse occurs (Fig 6).

The sets of acceleration amplitude $a_{0}$ and pulse period $T_{0}$ obtained by this procedure define the overturning domain, as the frontier beyond which the structure would collapse. The numerical domain obtained by this procedure could be compared with that provided by Eq. (4) referred to the rigid block. It should be noted that, in this case, the structure is also subjected to the initial pulse ramp for values less than $\hat{a}_{0}^{s t}$ and furthermore the overturning does not only occur at the end of the pulse (Makris \& Konstantinidis, 2003), since when the excitation expires (i.e. for $\mathrm{t}>\mathrm{T}$ ), the model is let run with 
Fig. 5 Displacement timehistories of a control point for pushover analysis and dynamic pulse analyses

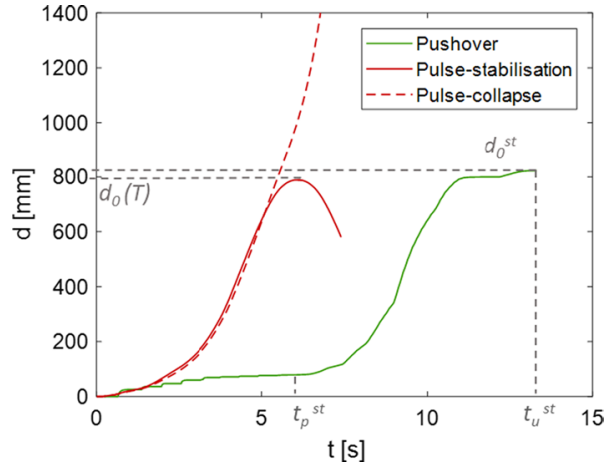

Fig. 6 Method for the construction of the overturning domain using brief and long pulses

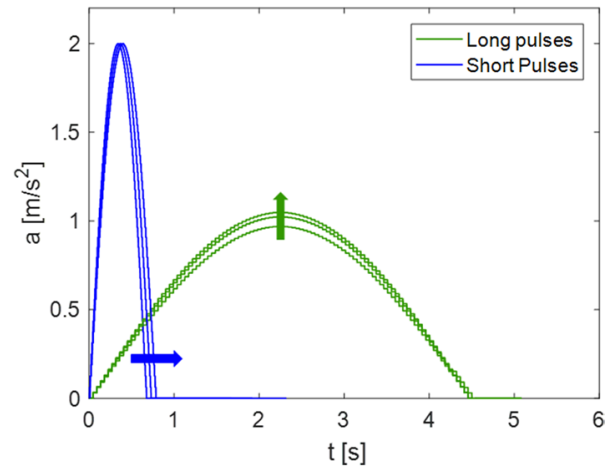

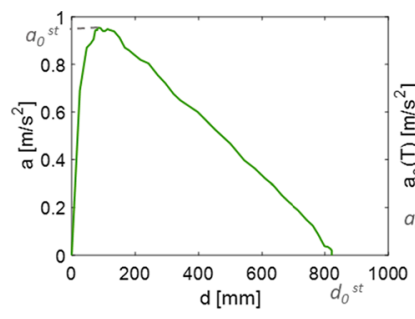

(a)

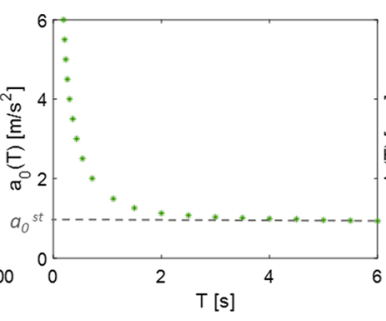

(b)

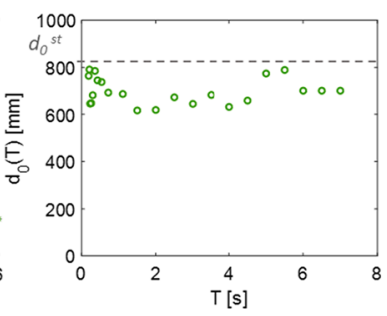

(c)

Fig. 7 Time, acceleration and control point displacement monitored at the proposed analyses. a Pushover curve b Overturning domain; c Displacement capacity for different pulse durations

horizontal acceleration equal to zero and, especially for short pulses, the displacement could increase and lead the structure to collapse well beyond the duration of the pulse.

The analyses also provide the failure mechanism and the displacement capacity, i.e. the maximum displacement $d_{0}(T)$ that the structure is able to sustain without collapsing (Fig. 5). It appears, from the analyses, that the displacement capacity does not depend on the pulse period and coincide with the value $d_{0}{ }^{s t}$ provided by pushover analysis as described in previous section. However, since small increments in the amplitude or in the period can lead the model to collapse or recovery, due to the unavoidable approximations, the maximum displacement $d_{0}(T)$ is generally a lower-bound estimate of the 
effective displacement capacity, which can be more easily estimated through pushover analysis (Fig. 7c).

By combining static pushover and dynamic analyses, the proposed approach provides: (1) the expected failure mechanism, (2) the pushover acceleration-displacement capacity curve (Fig. 7a), (3) the overturning domain in terms of pulse amplitude and duration (Fig. 7b), (4) the displacement capacity (Fig. 7c).

As will be shown in the next section, the proposed numerical approach can be directly integrated in a procedure for design and assessment of the churches against the out-ofplane overturning of the façade since:

(1) The prediction of the collapse mechanism guides the design of any seismic mitigation measures;

(2) The capacity curve can be directly compared with the expected seismic demand spectrum to estimate the seismic risk (Lagomarsino 2015);

(3) The overturning domain can be directly compared with the rocking demand spectra to estimate the ground motion required for overturning (Makris and Konstantinidis 2003; Mauro et al. 2015).

\section{Application to single-nave churches}

Seven single-nave churches belonging to the area surrounding the city of L'Aquila (Fig. 8), have been considered for the application of the above-described procedure for seismic assessment. The churches are named: Sant'Andrea in Stiffe, Santa Maria degli Angeli, Santa Maria ad Cryptas, Santa Maria del Presepe, San Paolo ad Peltuinum, San Sisto, Santo Stefano. These churches, after the earthquake on April 6th 2009, suffered some damages: some experienced the detachment of the façade and the triggering of the overturning mechanism, without collapsing, some others were secured with chains that prevented from failing out-of-plane.

In this section the churches are briefly described, and their geometrical and mechanical properties are provided. An overall view of the churches is shown in Fig. 9, while the detailed characteristics of the connections between the façade and the side wall is shown in Fig. 10. In this latter figure the photographic survey after distortion correction is shown with superimposed recognition of masonry blocks. During the photographic survey, the dimensions of the facade and side walls of the churches are surveyed, detecting the size and arrangement of the stone elements. The discrete element model is finally constructed according to the actual masonry pattern recognized by the survey. It could be argued that the model built as explained, only considers the masonry pattern of the facing of masonry, while the internal arrangement of the stones is not accounted for. In other words, since the model is in $2 \mathrm{D}$ and the third dimension is simply considered by providing the thickness, the resulting model considers each block as extruded for the entire thickness of the wall. This is clearly a limitation of the proposed approach which depends on its two-dimensional character, so some care is required in the construction of the model. For example, in cases where the façade differs significantly from the wall core, it is possible to attribute to the model a reduced thickness equal to that of the face alone.

In Table 1 the geometrical characteristics of the churches are listed: $l_{f}$ and $b_{f}\left(l_{s}\right.$ and $\left.b_{s}\right)$ are the length and the thickness of the façade (of the lateral wall) $h_{f}$ and $h_{s}$ their heights. In Table 2 the mechanical properties are reported: $\gamma_{f}$ and $\gamma_{s}$ are the specific weight of the façade and the side walls, respectively, $K_{N f}$ and $K_{N s}$ the normal stiffness of the joints, $K_{S f}$ 


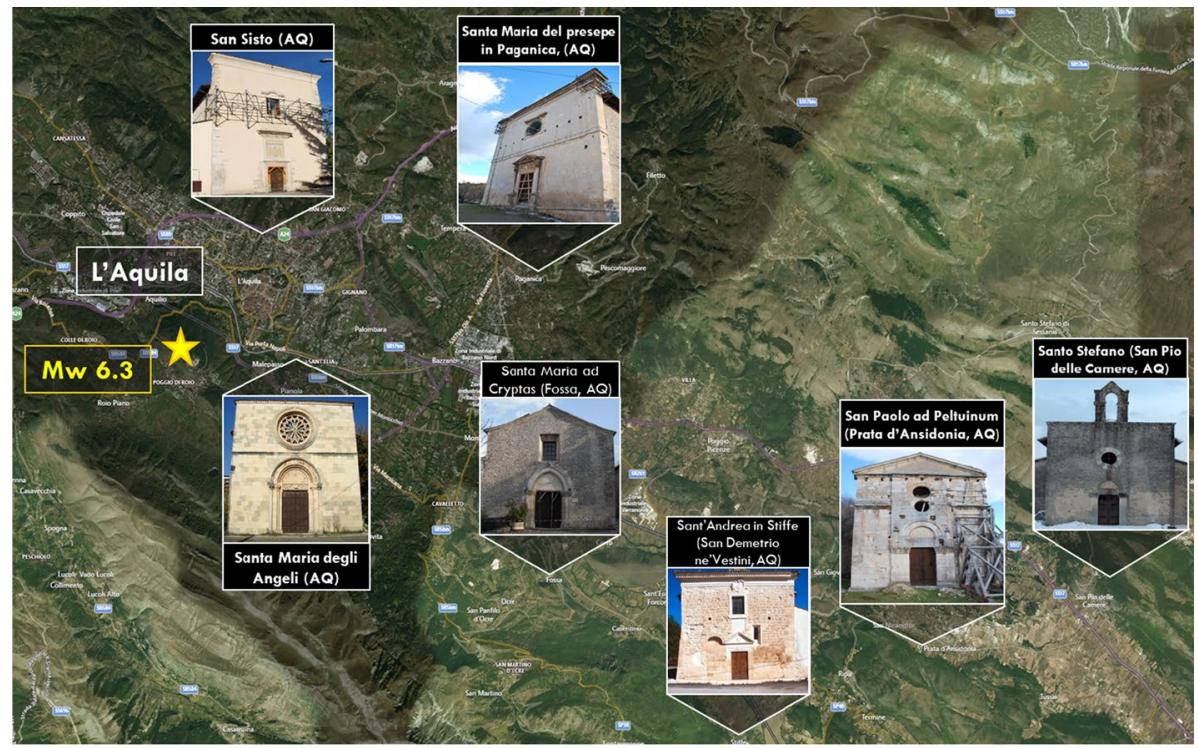

Fig. 8 Location of the case studies and the epicentre of the 6th April 2009 L'Aquila earthquake

and $K_{S s}$ the corresponding shear stiffness, while the friction angle $\varphi$ of the contacts is set equal to $30^{\circ}$.

\subsection{Description of the churches}

The Church of Sant'Andrea in Stiffe is in the municipality of San Demetrio ne'Vestini (AQ). The original structure dates to the X Century a.c., but the current structure derives from the renovation works of the XIV century, when the semicircular apse was replaced with a rectilinear one. The building has almost a rectangular plan, with a front width of about $8 \mathrm{~m}$ and a length of about $25 \mathrm{~m}$. The façade has a horizontal crown, the masonry texture is made with rough-hewn stones with regular recurrences.

The Church of Santa Maria degli Angeli is located in the city of L'Aquila, the structure was built on the remains of an existing building. The niches along the nave show signs of subsequent infill and repeated rearrangements. The building has almost a rectangular plan, with a front width of about $10 \mathrm{~m}$ and a length of about $16 \mathrm{~m}$. The side walls have two regular rectangular windows on each side, the masonry is in small and poorly worked stones.

The Church of Santa Maria ad Cryptas is in the municipality of Fossa (AQ), the structure was probably built between the XII and XIII Century a.c. and it preserves frescoes of great value and beauty. Inside there is the pre-existence of some vaulted parts no longer present, while the roof with wooden trusses, partially renovated in the XX century, is currently visible. The structure opens into a single hall measuring approximately $10 \mathrm{~m}$ by $17 \mathrm{~m}$, ending with an apse not aligned with the walls of the church. The masonry is made of rough-hewn stone blocks, typical of the area around the city of L'Aquila. 

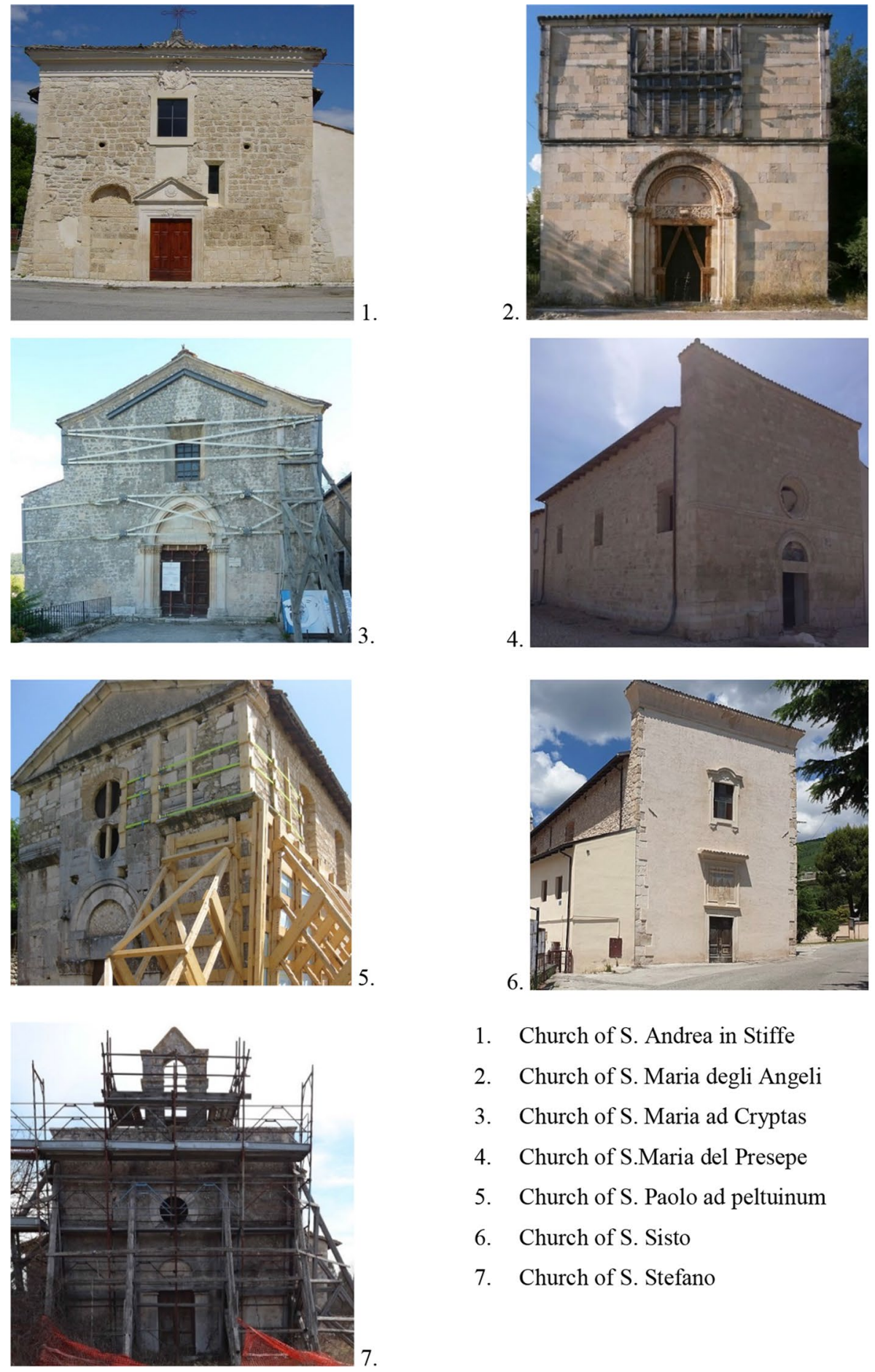

1. Church of S. Andrea in Stiffe

2. Church of S. Maria degli Angeli

3. Church of S. Maria ad Cryptas

4. Church of S.Maria del Presepe

5. Church of S. Paolo ad peltuinum

6. Church of S. Sisto

7. Church of S. Stefano

Fig. 9 View of the single nave churches under study 

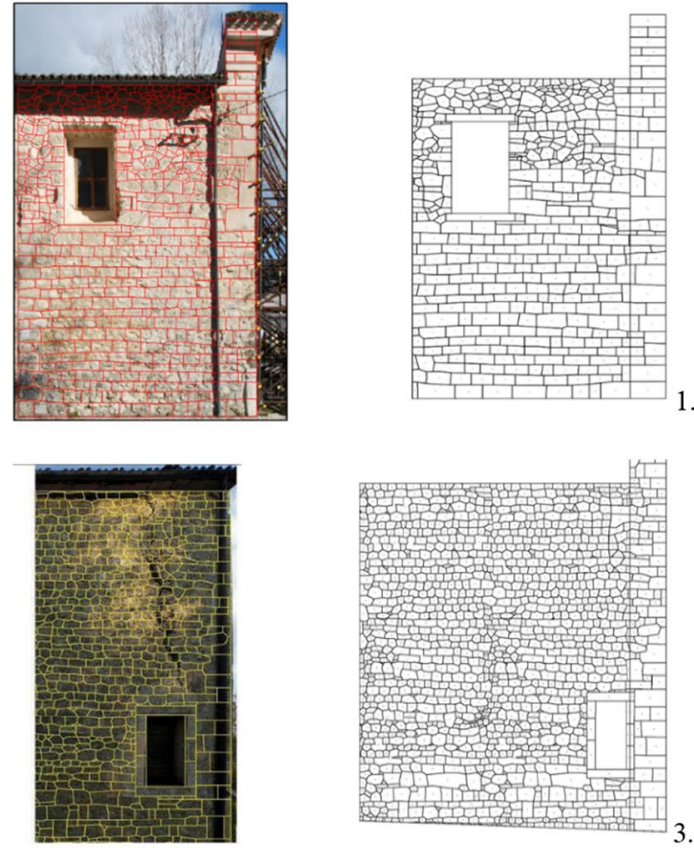

1. 2.
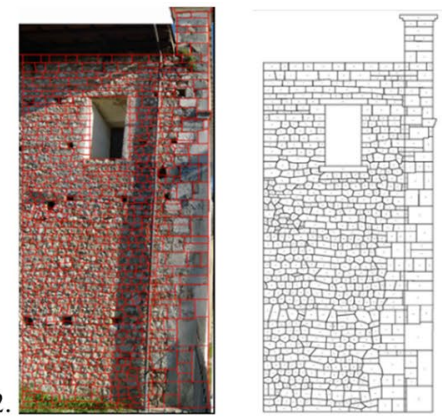

4.
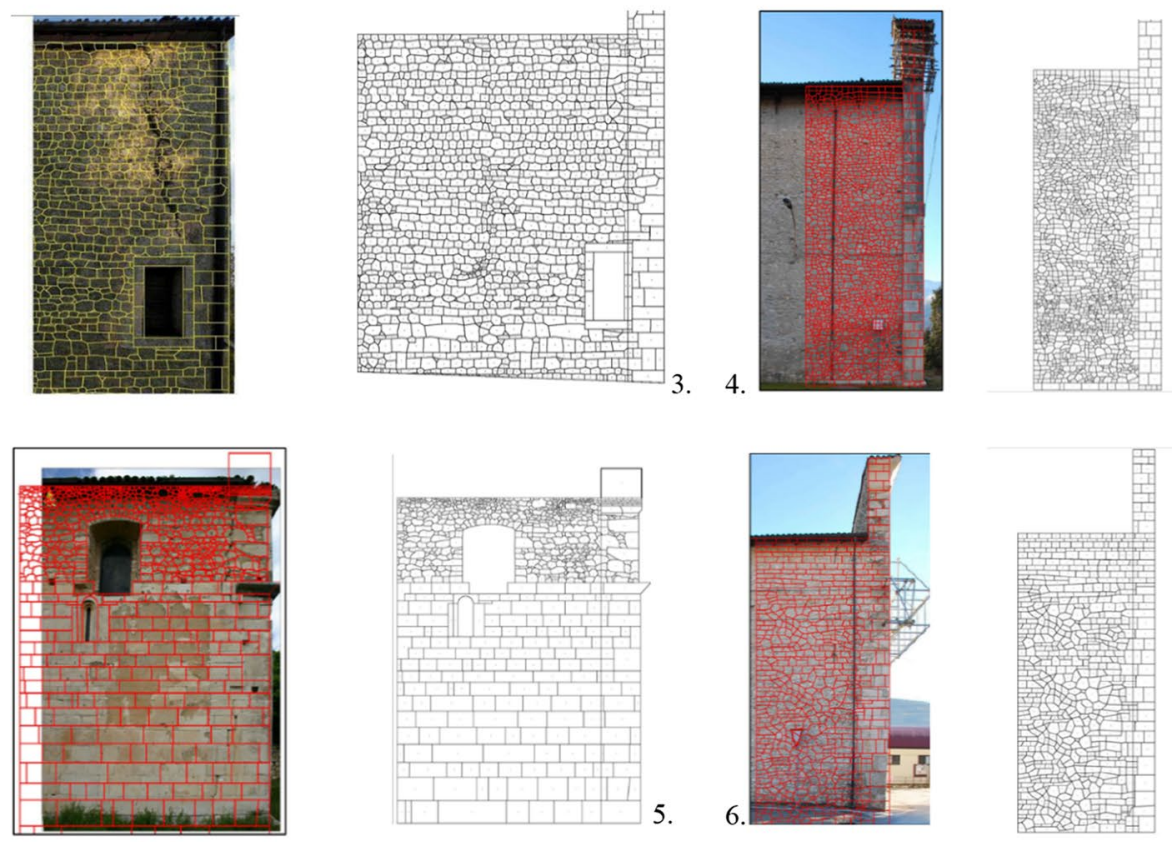

1. Church of S. Andrea in Stiffe

2. Church of S. Maria degli Angeli

3. Church of S. Maria ad Cryptas

4. Church of S.Maria del Presepe

5. Church of S. Paolo ad peltuinum

6. Church of S. Sisto

7. Church of S. Stefano

Fig. 10 Photographic survey after correction of distortions with superimposed recognition of block masonry and resulting discrete element model 
Table 1 Geometric characteristics of the churches

\begin{tabular}{|c|c|c|c|c|c|c|c|}
\hline & \multirow[t]{2}{*}{ Church } & \multicolumn{3}{|c|}{ Façade } & \multicolumn{3}{|c|}{ Side wall } \\
\hline & & $\overline{l_{f}[\mathrm{~m}]}$ & $b_{f}[\mathrm{~m}]$ & $\overline{h_{f}[\mathrm{~m}]}$ & $l_{s}[\mathrm{~m}]$ & $b_{s}[\mathrm{~m}]$ & $h_{s}[\mathrm{~m}]$ \\
\hline 1 & Sant'Andrea in Stiffe & 8.60 & 0.70 & 8.15 & 6.00 & 0.70 & 6.80 \\
\hline 2 & Santa Maria degli Angeli & 10.00 & 0.70 & 10.00 & 4.30 & 0.50 & 8.80 \\
\hline 3 & Santa Maria ad Cryptas & 10.20 & 0.86 & 9.50 & 7.40 & 1.00 & 7.90 \\
\hline 4 & Santa Maria del Presepe & 15.15 & 1.00 & 17.50 & 5.75 & 1.00 & 14.33 \\
\hline 5 & San Paolo ad Peltuinum & 8.00 & 1.07 & 9.60 & 5.50 & 0.80 & 8.80 \\
\hline 6 & San Sisto & 9.95 & 0.75 & 13.30 & 4.70 & 1.40 & 10.40 \\
\hline 7 & Santo Stefano & 7.00 & 0.70 & 7.70 & 5.50 & 0.60 & 6.00 \\
\hline
\end{tabular}

Table 2 Mechanical characteristics of the churches

\begin{tabular}{|c|c|c|c|c|c|c|c|c|}
\hline & \multirow{2}{*}{\multicolumn{2}{|c|}{ Church }} & \multicolumn{3}{|l|}{ Façade } & \multicolumn{3}{|l|}{ Side wall } \\
\hline & & & $\gamma_{f}\left[\mathrm{Kg} / \mathrm{m}^{3}\right]$ & $K_{N f}[\mathrm{~Pa} / \mathrm{m}]$ & $K_{S f}[\mathrm{~Pa} / \mathrm{m}]$ & $\gamma_{s}\left[\mathrm{Kg} / \mathrm{m}^{3}\right]$ & $K_{N s}[\mathrm{~Pa} / \mathrm{m}]$ & $K_{S s}[\mathrm{~Pa} / \mathrm{m}]$ \\
\hline 1 & \multicolumn{2}{|c|}{ Sant'Andrea in Stiffe } & 2100 & $2.94 \mathrm{e} 10$ & $8.31 \mathrm{e} 9$ & 2100 & $4.06 \mathrm{e} 9$ & $1.35 \mathrm{e} 9$ \\
\hline 2 & \multicolumn{2}{|c|}{ Santa Maria degli Angeli } & 2100 & $2.90 \mathrm{e} 10$ & $8.31 \mathrm{e} 9$ & 2000 & $4.10 \mathrm{e} 10$ & $1.35 \mathrm{e} 9$ \\
\hline 3 & \multicolumn{2}{|c|}{ Santa Maria ad Cryptas } & 2100 & $3.55 \mathrm{e} 10$ & $1.18 \mathrm{e} 10$ & 2100 & $1.16 \mathrm{e} 10$ & $3.87 \mathrm{e} 9$ \\
\hline 4 & \multicolumn{2}{|c|}{ Santa Maria del Presepe } & 2200 & $6.17 \mathrm{e} 10$ & $2.06 \mathrm{e} 10$ & 1900 & $5.80 \mathrm{e} 9$ & $1.93 \mathrm{e} 9$ \\
\hline \multirow[t]{2}{*}{5} & \multirow{2}{*}{$\begin{array}{l}\text { San Paolo ad } \\
\text { Peltuinum }\end{array}$} & Upper & 1900 & $2.19 \mathrm{e} 10$ & $7.30 \mathrm{e} 9$ & 1900 & $6.96 \mathrm{e} 9$ & $2.32 \mathrm{e} 9$ \\
\hline & & Lower & 2200 & $2.69 \mathrm{e} 10$ & $8.97 \mathrm{e} 9$ & 2200 & $2.85 \mathrm{e} 9$ & $9.50 \mathrm{e} 8$ \\
\hline 6 & San Sisto & & 2200 & $4.05 \mathrm{e} 10$ & $1.35 \mathrm{e} 10$ & 2100 & $1.64 \mathrm{e} 10$ & $5.45 \mathrm{e} 9$ \\
\hline \multirow[t]{2}{*}{7} & Santo Stefano & Upper & 2200 & $3.33 \mathrm{e} 10$ & $1.11 \mathrm{e} 10$ & 1900 & $3.48 \mathrm{e} 9$ & $1.16 \mathrm{e} 9$ \\
\hline & & Lower & & & & 2100 & $2.61 \mathrm{e} 9$ & $8.70 \mathrm{e} 8$ \\
\hline
\end{tabular}

The Church of Santa Maria del Presepe is in the municipality of Paganica (AQ). The original structure dates around 1605 (Doglioni, F, Moretti, A, and Petrini 1994). Similarly to Sant'Andrea in Stiffe, the façade has a rectangular shape, with a front width of $15.5 \mathrm{~m}$ and a height of $17.6 \mathrm{~m}$, covered in square ashlars, while the masonry of the side wall consists of irregular stones.

The Church of San Paolo ad Peltuinum is located in the municipality of Prata d'Ansidonia (AQ). From its first construction between the seventh and eighth centuries, the church has undergone many changes under Lombard, Benedictine, Cistercian, Renaissance and eighteenth-century influences. The church presents a cross plan with a single nave and a transept, without apse, with an overall length of about $24 \mathrm{~m}$. Two different types of masonry can be identified: the lower part is made of large parallelepiped blocks and dates back to the medieval period, while the upper part, made of small irregular stones, is the result of a more recent reconstruction.

The Church of San Sisto dates back to the VIII century a.C. and is located in the city of L'Aquila. The façade has a rectangular shape with an horizontal crown. The building has a single nave structure that borders with lower buildings on the left, which were probably previously part of the church itself. The façade has a rectangular shape, with a front width 
of $10 \mathrm{~m}$ and a height of $13 \mathrm{~m}$, covered in square ashlars, while the masonry of the transversal wall is in small and poorly worked stones.

The Church of Santo Stefano is located in the municipality of San Pio delle Camere (AQ). There is no precise information regarding the date of construction of the Church, but an analysis of the walls shows a typical building typology in Abruzzo from the late thirteenth century to the early fourteenth century. After the second half of the XIII century transept and apse should have been realized. The building has a Latin cross plan, a single nave with a transept and apse. The hall has a rectangular plan with a width of $7 \mathrm{~m}$, a length of $20 \mathrm{~m}$ and a maximum height of $7 \mathrm{~m}$. The façade is made of square well-arranged stone blocks. The side walls, on the other hand, are made of irregularly shaped stones, with two poorly connected faces. Three different types of masonry were considered for this church, one for the façade and two for the side wall consisting of large blocks in the lower part and masonry with irregular minute stones in the upper part.

\section{Numerical results}

In this section, the numerical and analytical results are presented for the seven churches described above. As a first experimental validation of the proposed methodology, the collapse mechanisms detected through the DEM are compared to the the crack pattern caused by the 2009 earthquake for the two churches of San Paolo and S. Maria ad Cryptas, which suffered the most severe damages with the earthquake. The comparison confirms the great capability of the model to foresee the weakest joints where the detachment occurs and the resulting collapse mechanism, as shown in Fig. 11, where the mechanism provided by the analysis is superposed to the actual crack pattern.

In order to compare the Distinct Element (DE) numerical results with the conventional rigid-body (RB) analysis, in Figs. 12, 13, 14, 15, 16, 17 and 18 for each church, the failure mechanism, the corresponding stability domain under sinusoidal pulses and the pushover curve provided by DEM are shown (in green line) superposed on those (in red line) provided by Eqs. (1) and (4) when considering the façade as a rigid body free to rotate outwards.

The numerical analysis of the church of Sant'Andrea in Stiffe provides the crack pattern shown in Figure A, in which the overturning mechanism involves a non-negligible part of the side wall due to the effectiveness of the connection, ensured by the modelling of the blocks arranged as in reality. The acceleration and displacement capacities are respectively: $a_{0}^{s t}=1.36 \mathrm{~m} / \mathrm{s}^{2}$ and $d_{0}^{s t}=912 \mathrm{~mm}$, with a substantial increase as compared to the rigid block model (Fig. 12).

The analysis of the church of San Paolo exhibits a similar increase (of about 50\%) in acceleration capacity $\left(\hat{a}_{0}{ }^{s t}=1.09 \mathrm{~m} / \mathrm{s}^{2} a_{0}{ }^{s t}=1.71 \mathrm{~m} / \mathrm{s}^{2}\right)$ while almost no increment was found in the displacement capacity, which remains about $1000 \mathrm{~mm}$, for both the $\mathrm{RB}$ and DE analyses. For brief pulses (lower than $1 \mathrm{~s}$ ), RB and DE provide almost the same results, while for longer pulses, a substantial increase in the acceleration capacity provided by DE is observed. The resulting collapse mechanism provides an explanation for this observed. Due to the quality of the masonry, which consists of large square blocks in the basement, the rotation hinge is located at approximately half of the height (Fig. 13a). Therefore, the acceleration capacity increases because of the reduced 


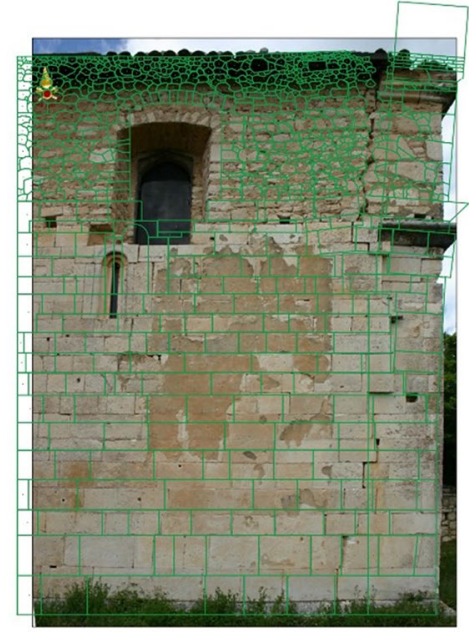

(a)

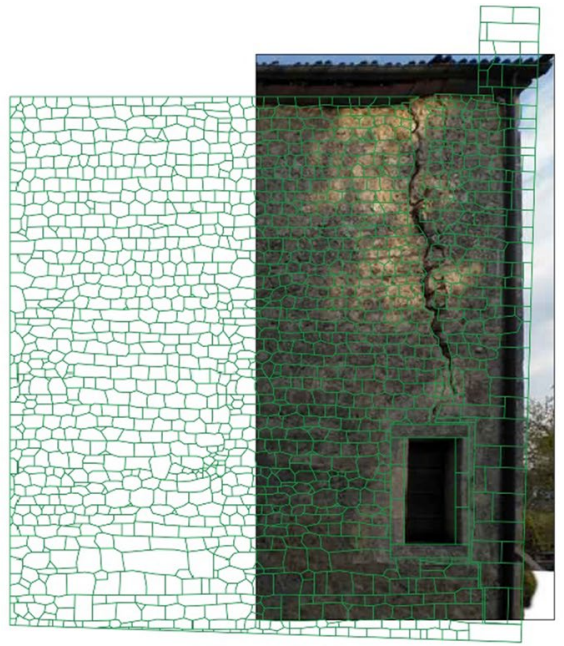

(b)

Fig. 11 Comparison between the damages caused by the 2009 earthquakes and the failure pattern provided by numerical analysis: a Church of San Paolo; b Church of S.Maria ad Cryptas

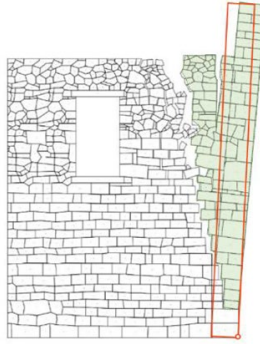

(a)

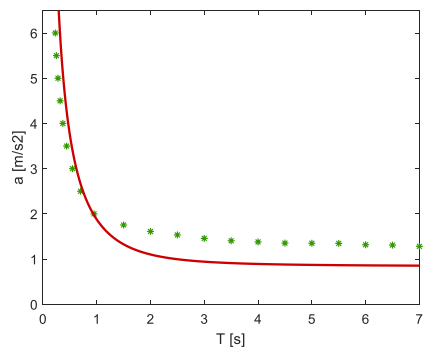

(b)

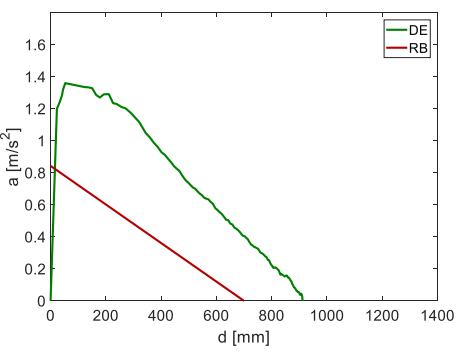

(c)

Fig. 12 Church of Sant'Andrea in Stiffe: a Predicted crack pattern and failure mechanism according to distinct element analysis; b rocking domain; c pushover analysis

slenderness of the part affected by the overturning, while the displacement capacity, which is governed by the thickness of the façade, remains almost unchanged.

The church of San Sisto (Fig. 14) has the lower acceleration capacity as compared to other case studies presented in this paper, due to the high slenderness of the façade: $\hat{a}_{0}{ }^{s t}=0.55 \mathrm{~m} / \mathrm{s}^{2}$, while $\hat{d}_{0}{ }^{s t}=750 \mathrm{~mm}$. The stability of the façade is assured by chains that, however, are not included in the model. The DE analyses show a strong increase in both acceleration (of about $50 \%$ i.e. $a_{0}{ }^{s t}=0.92 \mathrm{~m} / \mathrm{s}^{2}$ ) and displacement capacity (of about $65 \%$, i.e. $d_{0}{ }^{s t}=1246 \mathrm{~mm}$ ), thanks to the beneficial effect of the connection between the façade and the transversal wall.

The numerical DE analysis of the church of Santa Maria degli Angeli provides an acceleration capacity $a_{0}^{s t}=0.8 \mathrm{~m} / \mathrm{s}^{2}$ and a displacement capacity $d_{0}^{s t}=872 \mathrm{~mm}$. There is an increase for the displacement of about $20 \%$ as compared to the RB model which presents 


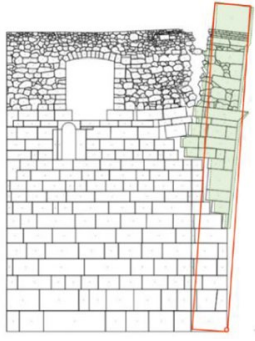

(a)

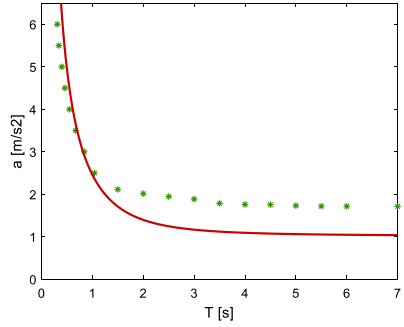

(b)

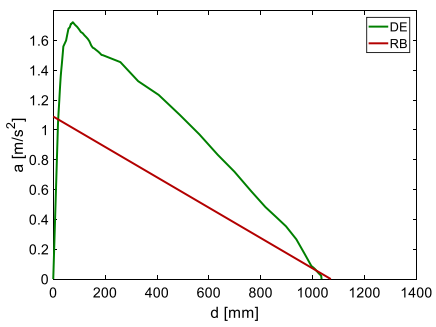

(c)

Fig. 13 Church of San Paolo: a Predicted crack pattern and failure mechanism according to distinct element analysis; b rocking domain; c pushover analysis

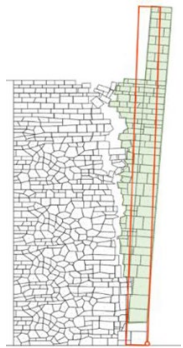

(a)

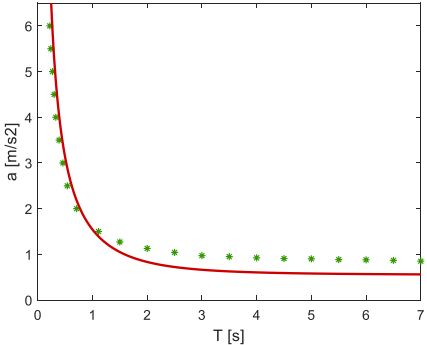

(b)

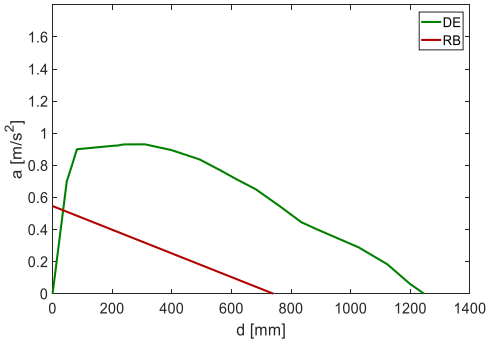

(c)

Fig. 14 Church of San Sisto: a Predicted crack pattern and failure mechanism according to distinct element analysis; $\mathbf{b}$ rocking domain; c pushover analysis

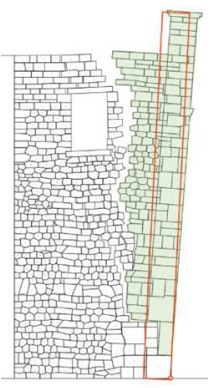

(a)

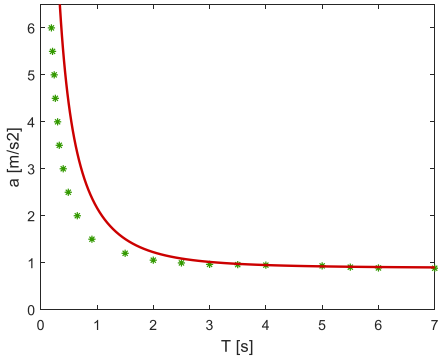

(b)

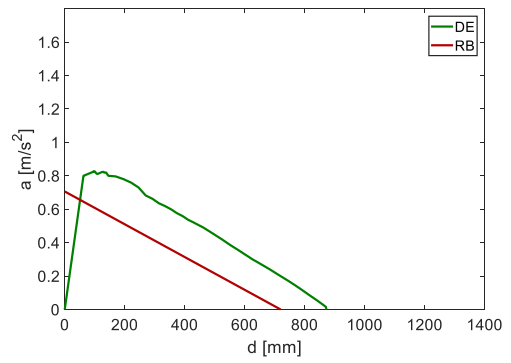

(c)

Fig. 15 Church of Santa Maria degli Angeli: a Predicted crack pattern and failure mechanism according to distinct element analysis; b rocking domain; c pushover analysis

$\widehat{a}_{0}^{s t}=0.69 \mathrm{~m} / \mathrm{s}^{2}$ and and $\widehat{d}_{0}^{s t}=700 \mathrm{~mm}$ (Figure C). Even though the failure mechanism shows a non-negligible part of the lateral wall involved in the collapse mechanism (Figure A), thanks to a good interlocking of the stones, its stabilizing effect is only marginal as a consequence of the small thickness of the lateral wall which is only about $5 \%$ of the length of the façade. 


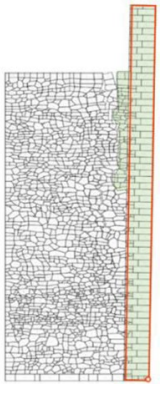

(a)

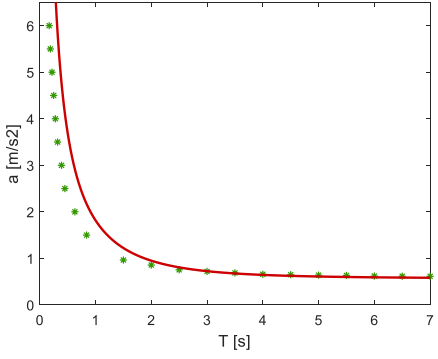

(b)

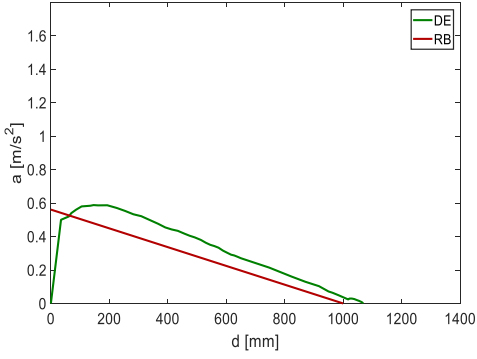

(c)

Fig. 16 Church of Santa Maria del Presepe: a Predicted crack pattern and failure mechanism according to distinct element analysis; b rocking domain; c pushover analysis

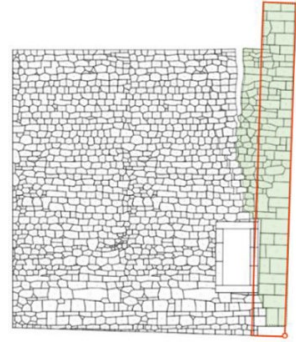

(a)

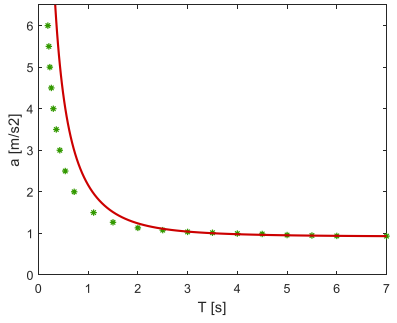

(b)

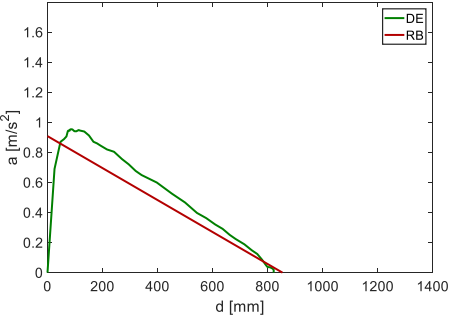

(c)

Fig. 17 Church of Santa Maria ad Cryptas: a Predicted crack pattern and failure mechanism according to distinct element analysis; b rocking domain; c pushover analysis

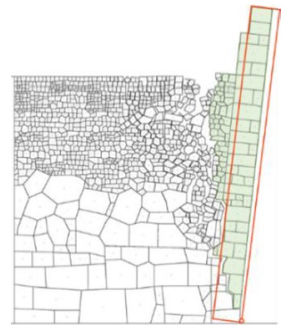

(a)

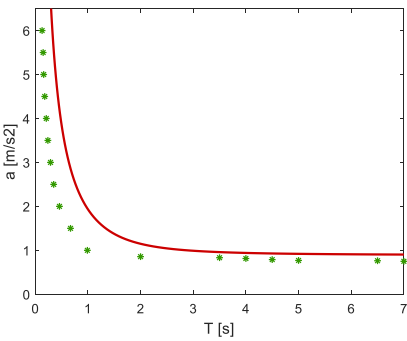

(b)

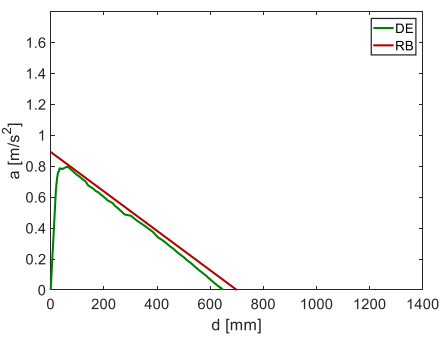

(c)

Fig. 18 Church of Santo Stefano: a Predicted crack pattern and failure mechanism according to distinct element analysis; $\mathbf{b}$ rocking domain; $\mathbf{c}$ pushover analysis

The DE analysis of the church of Santa Maria del Presepe provides an acceleration capacity $a_{0}^{s t}=0.59 \mathrm{~m} / \mathrm{s}^{2}$ and a displacement capacity $d_{0}^{s t}=1068 \mathrm{~mm}$. Numerical curve almost coincides with the theoretical one (Figure B), apart from a slight increase of the 
displacement capacity of about $7 \%\left(\widehat{d}_{0}{ }_{0} t=1000 \mathrm{~mm}\right)$ and a slight decrease of the stability domain under short period pulses (Figure C). Indeed, the failure mechanism shows that only a negligible part of the lateral wall is involved in the collapse mechanism (Figure A).

The church of Santa Maria ad Cryptas (Figure) exhibits almost no increment in acceleration and displacement capacity when compared to the rigid block. Numerical and analytical acceleration capacities are equal to: $a_{0}{ }^{s t}=0.95 \mathrm{~m} / \mathrm{s}^{2}, \hat{a}_{0}{ }^{s t}=0.93 \mathrm{~m} / \mathrm{s}^{2}$ while displacement capacities are $d_{0}^{s t}=822 \mathrm{~mm}$ and $\hat{d}_{0}{ }_{0}^{s t}=900 \mathrm{~mm}$. For long pulses, the capacity of the DE and $\mathrm{RB}$ models are almost equal, while for high frequencies actions, numerical curves lays below the analytical one.

Even though the failure mechanism shows a non-negligible part of the lateral wall involved in the collapse mechanism (Figure), its stabilizing effect is not relevant as a consequence of the small thickness $b_{s}$ of the lateral wall.

The analysis of the church of Santo Stefano exhibits a slight underestimate (Fig. 18), for both, the acceleration $\left(a_{0}{ }^{s t}=0.80 \mathrm{~m} / \mathrm{s}^{2}, \hat{a}_{0}{ }^{s t}=0.89 \mathrm{~m} / \mathrm{s}^{2}\right)$ and displacement $\left(d_{0}{ }^{s t}=647 \mathrm{~mm} \hat{d}\right.$ $0^{s t}=750 \mathrm{~mm}$ ) capacities provided by the $\mathrm{DE}$ as compared to the $\mathrm{RB}$ analysis. In this case, the poor and irregular characteristic of masonry result in a further trust of the lateral wall, rather than in a restrain under the seismic action.

\section{Discussion and conclusions}

The 2009 earthquake caused severe damage to the architectural heritage with several churches that experienced the out-of-plane overturning of the façade. In current practice, the stability of the façade with respect to overturning, is carried out by assuming that the masonry remains monolithic and neglecting the restraint provided by the lateral walls through the corner stones. Aiming at proposing a general framework to assess the seismic capacity of collapse mechanisms of masonry structures and evaluate the efficacy of seismic prevention measures, an approach based on a refined model of the actual pattern of masonry through the Distinct Element Method (DEM) is illustrated.

The seismic response of seven masonry churches located at L'Aquila has been studied through dynamic pulse-based and quasi-static pushover analyses, with both analytical and numerical approach. The influence of the quality of masonry and the beneficial effect of the interlocking of the façade with the lateral wall has been investigated and the results compared with the conventional rigid block $(\mathrm{RB})$ analysis.

The proposed approach provides a reliable estimate of the expected collapse mechanism under seismic loading as shown by comparison with the actual crack pattern experienced by the churches during the earthquake. Accurate prediction of the collapse mechanism proves to be a useful tool for both, seismic assessment and eventual design of earthquake mitigation measures. In particular, the seismic assessment could be conducted either with static pushover, by simply comparing the capacity curve provided by the analysis with the expected seismic demand resulting from seismic hazard, or with dynamic pulses, by comparing the overturning domain provided by the analysis with the expected earthquake rocking demand spectra. With regard to the evaluation of seismic mitigation measures, the analysis can be easily repeated by introducing the actual characteristics of the intervention into the model.

From the sample of churches surveyed, the results in terms crack pattern are not affected by the duration of the dynamic pulse and are quite similar to those obtained with static 
pushover, apart from very short period pulses, which usually provide a more spread crack pattern. A more smeared crack pattern may also be the result of the assumptions of no cohesion and tensile strength in the DEM. Generally, both the displacement and acceleration capacities determined by the DEM, are greater (Sant'Andrea in Stiffe, Santa Maria degli Angeli, Santa Maria del Presepe San Sisto) or equal (San Paolo, Santa Maria ad Cryptas) than those of the conventional RB model, due to the beneficial effect of façade interlocking. The analytical RB model still represents, a reliable and effective instrument for the seismic assessment of masonry that generally provides a lower bound estimate. When the characteristics of the masonry in terms of bock shape and arrangement are such as to prevent the complete detachment of the façade from the side walls, the latter determine a significant increase in the out-of-plane capacity with the upward displacement of the tilting hinge and a corresponding reduction in the slenderness of the part subject to overturning, and an increase in the stabilising moment of the side wall involved in the mechanism. Such a contribution, which is generally neglected in current practice, would result in a greater dissipation capacity under seismic load and a reduced need for seismic mitigation interventions.

In the sample of churches under study about half of the cases show the fair reliability of the conventional RB model with deviations of less than $10 \%$ with respect to the DE model. Moreover, the DE analyses display a mechanism in which the façade remains almost monolithic during overturning, according to the assumption of RB analysis. However, in the remaining half of the cases, the RB model estimates just about $60 \%$ of the actual capacity in terms of acceleration and about $80 \%$ of the actual capacity in terms of displacement (Table 3), because of neglecting the connection between the façade and the side wall.

For brief pulses, it could be noted from the overturning domains that most of the numerical solutions result in a lower capacity with respect to the conventional RB analysis. However, as recalled in Sect. 3.4, the two analysis are not directly comparable due to the differences in the applied pulse since, contrary to what assumed by Housner (1963), for short period excitations, overturning of the façade in numerical analysis usually occurs long after the pulse action has ended. Therefore, the pulse-based numerical analyses are more severe than the analytical estimates.

In the sample of churches under study, the portion of the structure mobilised by failure only represents a fraction ranging from 15 to $35 \%$ of the overall mass, including the lateral walls. This clearly shows the local character of the collapse mechanism and the need to determine the failing mass $m^{*}$ as explained in Sect. 3.3, for the evaluation of the capacity

Table 3 Comparison of results obtained through the Discrete Element and conventional Rigid Body models

\begin{tabular}{|c|c|c|c|c|c|c|}
\hline \multirow[t]{2}{*}{ Church } & \multicolumn{2}{|c|}{ DEM results } & \multicolumn{2}{|c|}{ RBM results } & \multicolumn{2}{|l|}{ Variation } \\
\hline & $\mathrm{a}_{0}{ }^{\mathrm{st}}\left[\mathrm{m} / \mathrm{s}^{2}\right]$ & $\mathrm{d}_{0}{ }^{\mathrm{st}}[\mathrm{mm}]$ & $\hat{\mathrm{a}}_{0}^{\mathrm{st}}\left[\mathrm{m} / \mathrm{s}^{2}\right]$ & $\widehat{d}_{0}{ }^{\mathrm{st}}[\mathrm{mm}]$ & $\left(\mathrm{a}_{0}{ }^{\mathrm{st}}-\hat{\mathrm{a}}_{0}{ }^{\mathrm{st}}\right) / \hat{\mathrm{a}}_{0}^{\mathrm{st}}$ & $\left(\mathrm{d}_{0}{ }^{\mathrm{st}}-\widehat{d}_{0}{ }^{\mathrm{st}}\right) / \widehat{d}_{0}{ }^{\mathrm{st}}$ \\
\hline Sant'Andrea in Stiffe & 1.36 & 912 & 0.84 & 700 & $62 \%$ & $30 \%$ \\
\hline Santa Maria degli Angeli & 0.81 & 872 & 0.69 & 700 & $17 \%$ & $25 \%$ \\
\hline Santa Maria ad Cryptas & 0.95 & 822 & 0.93 & 860 & $2 \%$ & $-9 \%$ \\
\hline Santa Maria del Presepe & 0.59 & 1068 & 0.56 & 1000 & $5 \%$ & $7 \%$ \\
\hline San Paolo ad Peltuinum & 1.71 & 1033 & 1.09 & 1000 & $57 \%$ & $3 \%$ \\
\hline San Sisto & 0.92 & 1246 & 0.55 & 750 & $67 \%$ & $66 \%$ \\
\hline Santo Stefano & 0.80 & 647 & 0.89 & 700 & $-10 \%$ & $-8 \%$ \\
\hline
\end{tabular}


curve and the estimate of the ultimate displacement. When referring to the mass of the façade, the failing mass $m^{*}$ usually ranges between 95 and $115 \%$. The higher mass is mobilised in the mechanism, the greater contribution arises from the lateral walls, resulting in the increase in the out-of-plane capacity. On the contrary, if a smaller mass of the façade is mobilised, there is no direct relationship with the seismic capacity, since it could be either the result of a higher position of the rotation hinge with a corresponding increase in capacity, or a lower contribution of the side walls with a resulting lower capacity.

No significant differences emerge between dynamic analyses, when varying the pulse period, nor in terms of failure mechanism neither in terms of displacement capacity, proving that the problem is mainly controlled by overall geometry of the church and the interlocking provided by the masonry, rather than on the characteristics of seismic input. The substantial stability of the solution regardless of the characteristics of the input confirms the robustness of the proposed approach and its reliability in the assessment of local collapse mechanism.

The proposed approach could appear to be cumbersome since it requires the appraisal of the actual stone masonry units connecting the façade to the side wall. In some cases, the stone units are covered by the plaster and their recognition requires instrumental inspections. However, as known to ancient builders, the corner stone plays a substantial role in ensuring the stability of the wall against overturning. Therefore, as digital survey techniques become more available, reproducing the actual masonry pattern in key parts of the building become easier and including it in a computational tool is a step towards the reliable assessment of historic masonry structures.

Author contributions Gianmarco de Felice: Conceptualization, Writing-review and editing, Funding acquisition, Supervision. Rebecca Fugger: Formal Analysis and Investigation, Writing -original draft, Visualization, Data Curation. Francesca Gobbin: Conceptualization, Methodology, Formal Analysis and Investigation, Writing — original draft, Visualization, Data Curation.

Funding Open access funding provided by Università degli Studi Roma Tre within the CRUI-CARE Agreement. This work was funded by the research projects ReLUIS-DPC 2019-2021 and Regione Lazio SICURA 85-2017-115136.

Data Availability The authors confirm that the data supporting the findings of this study are available within the article.

\section{Declarations}

Conflict of interest The authors declare that there is no conflict of interest.

Code Availability Analyses are carried out though ad-hoc algorithms presented in (Gobbin et al. 2021) and developed inside the commercial software UDEC 6.0.

Open Access This article is licensed under a Creative Commons Attribution 4.0 International License, which permits use, sharing, adaptation, distribution and reproduction in any medium or format, as long as you give appropriate credit to the original author(s) and the source, provide a link to the Creative Commons licence, and indicate if changes were made. The images or other third party material in this article are included in the article's Creative Commons licence, unless indicated otherwise in a credit line to the material. If material is not included in the article's Creative Commons licence and your intended use is not permitted by statutory regulation or exceeds the permitted use, you will need to obtain permission directly from the copyright holder. To view a copy of this licence, visit http://creativecommons.org/licenses/by/4.0/. 


\section{References}

Adhikari RK, D'Ayala D (2020) 2015 Nepal earthquake: seismic performance and post-earthquake reconstruction of stone in mud mortar masonry buildings. Bull Earthq Eng 18:3863-3896. https://doi.org/ 10.1007/s10518-020-00834-y

Al Shawa O, de Felice G, Mauro A, Sorrentino L (2012) Out-of-plane seismic behaviour of rocking masonry walls. Earthq Eng Struct Dyn 41:949-968. https://doi.org/10.1002/eqe.1168

Asteris PG, Douvika MG, Apostolopoulou M, Moropoulou A (2017) Seismic and restoration assessment of monumental masonry structures. Materials (Basel) 10:895. https://doi.org/10.3390/ma10080895

Azevedo JJ, Sincraian G, Lemos JV (2000) Seismic behavior of blocky masonry structures. Earthq Spectra 16:337-365. https://doi.org/10.1193/1.1586116

Casapulla C, Giresini L, Lourenço PB (2017) Rocking and kinematic approaches for rigid block analysis of masonry walls: state of the art and recent developments. Buildings. https://doi.org/10.3390/buildings7 030069

Casolo S (2000) Modelling the out-of-plane seismic behaviour of masonry walls by rigid elements. Earthq Eng Struct Dyn 29:1797-1813. https://doi.org/10.1002/1096-9845(200012)29:12\%3c1797::AIDEQE987\%3e3.0.CO;2-D

Cundall PA (1971) A computer model for simulating progressive large-scale movements in blocky rock systems. In: Proocedings of the Symposio of the International Society of Rock Mechanics, Nancy 2

Doglioni F, Moretti A, and Petrini V (1994) Le chiese ed il terremto. Italy: LINT, Trieste

de Felice G (2011) Out-of-plane seismic capacity of masonry depending on wall section morphology. Int J Archit Herit 5:466-482. https://doi.org/10.1080/15583058.2010.530339

de Felice G, Mauro A (2010) On overturning of the façade in churches with single nave: some case studies from L'Aquila, Italy, 2009 Earthquake. Adv Mater Res 133-134:807-812

De Matteis G, Brando G, Corlito V (2019) Predictive model for seismic vulnerability assessment of churches based on the 2009 L'Aquila earthquake. Bull Earthq Eng 17:4909-4936. https://doi.org/10. 1007/s10518-019-00656-7

Da Porto F, Silva B, Costa C, Modena C (2012) Macro-scale analysis of damage to churches after earthquake in Abruzzo (Italy) on April 6, 2009. J Earthq Eng 16:739-758. https://doi.org/10.1080/13632 469.2012.685207

de Felice G, De Santis S, Lourenço PB, Mendes N (2017) Methods and challenges for the seismic assessment of historic masonry structures. Int J Archit Herit 11:143-160. https://doi.org/10.1080/15583058. 2016.1238976

Gobbin F, de Felice G, Lemos JV (2021) Numerical procedures for the analysis of collapse mechanisms of masonry structures using discrete element modelling. Eng Struct. https://doi.org/10.1016/J.ENGST RUCT.2021.113047

Heyman J (1966) The stone skeleton. Int J Solids Struct 2:249-279. https://doi.org/10.1016/0020-7683(66) 90018-7

Housner GW (1963) The behavior of inverted pendulum structures during earthquakes. Bull Seismol Soc Am 53:403-417

Iannuzzo A (2019) Energy based fracture identification in masonry structures: the case study of the church of "pieta dei turchini." J Mech Mater Struct 14:683-702. https://doi.org/10.2140/jomms.2019.14.683

Lagomarsino S (2015) Seismic assessment of rocking masonry structures. Bull Earthq Eng 13:97-128. https://doi.org/10.1007/s10518-014-9609-x

Lagomarsino S, Podestà S (2004a) Damage and vulnerability assessment of churches after the 2002 Molise, Italy, earthquake. Earthq Spectra 20:271-283. https://doi.org/10.1193/1.1767161

Lagomarsino S, Podestà S (2004b) Seismic vulnerability of ancient churches: II. Statistical analysis of surveyed data and methods for risk analysis. Earthq Spectra 20:395-412. https://doi.org/10.1193/1.17377 36

Lasciarrea WG, Amorosi A, Boldini D et al (2019) Jointed Masonry Model: a constitutive law for 3D soilstructure interaction analysis. Eng Struct 201:109803. https://doi.org/10.1016/j.engstruct.2019.109803

Lemos JV (2007) Discrete element modeling of masonry structures. Int J Archit Herit 1:190-213. https:// doi.org/10.1080/15583050601176868

Lemos JV (2012) Explicit codes in geomechanics - FLAC, UDEC and PFC. Innov Numer Model Geomech. https://doi.org/10.1201/b12130-17

Makris N, Konstantinidis D (2003) The rocking spectrum and the limitations of practical design methodologies. Earthq Eng Struct Dyn 32:265-289. https://doi.org/10.1002/eqe.223

Makris N, Zhang J (1999) Rocking Response and Overturning of Anchored Equipment under Seismic Excitations. Pacific Earthq Eng Res Cent 1-82 
Malena M, Portioli F, Gagliardo R et al (2019) Collapse mechanism analysis of historic masonry structures subjected to lateral loads: a comparison between continuous and discrete models. Comput Struct 220:14-31. https://doi.org/10.1016/j.compstruc.2019.04.005

Malomo D, Dejong MJ, Penna A (2018) Distinct Element modelling of the in-plane failure mechanisms of URM walls

Mauro A, de Felice G, DeJong MJ (2015) The relative dynamic resilience of masonry collapse mechanisms. Eng Struct 85:182-194. https://doi.org/10.1016/j.engstruct.2014.11.021

Meriggi P, de Felice G, De Santis S et al (2019) Distinct element modelling of masonry walls under out-ofplane seismic loading. Int J Archit Herit. https://doi.org/10.1080/15583058.2019.1615152

Milani G, Pizzolato M, Tralli A (2013) Simple numerical model with second order effects for out-of-plane loaded masonry walls. Eng Struct 48:98-120. https://doi.org/10.1016/J.ENGSTRUCT.2012.08.029

Milani G, Valente M (2015a) Failure analysis of seven masonry churches severely damaged during the 2012 Emilia-Romagna (Italy) earthquake: non-linear dynamic analyses vs conventional static approaches. Eng Fail Anal. https://doi.org/10.1016/j.engfailanal.2015.03.016

Milani G, Valente M (2015b) Comparative pushover and limit analyses on seven masonry churches damaged by the 2012 Emilia-Romagna (Italy) seismic events: possibilities of non-linear finite elements compared with pre-assigned failure mechanisms. Eng Fail Anal 47:129-161. https://doi.org/10.1016/j. engfailanal.2014.09.016

Milani G, Venturini G (2011) Automatic fragility curve evaluation of masonry churches accounting for partial collapses by means of 3D FE homogenized limit analysis. Comput Struct 89:1628-1648. https:// doi.org/10.1016/j.compstruc.2011.04.014

Ministero dei beni e delle Attività Culturali e del Turismo MIBACT (2015) Circular n.15 (30/04/15). Provisions on the protection of architectural heritage and seismic risk mitigation [In Italian]

Mordanova A, de Felice G (2018) Seismic assessment of archaeological heritage using discrete element method. Int J Archit Herit 00:1-13. https://doi.org/10.1080/15583058.2018.1543482

Pantò B, Cannizzaro F, Caddemi S, Caliò I (2016) 3D macro-element modelling approach for seismic assessment of historical masonry churches. Adv Eng Softw 97:40-59. https://doi.org/10.1016/j.adven gsoft.2016.02.009

Pantò B, Giresini L, Sassu M, Caliò I (2017) Non-linear modeling of masonry churches through a discrete macro-element approach. Earthq Struct 12:223-236. https://doi.org/10.12989/eas.2017.12.2.223

Penna A, Calderini C, Sorrentino L et al (2019) Damage to churches in the 2016 central Italy earthquakes. Bull Earthq Eng 17:5763-5790. https://doi.org/10.1007/s10518-019-00594-4

Portioli FPA (2020) Rigid block modelling of historic masonry structures using mathematical programming: a unified formulation for non-linear time history, static pushover and limit equilibrium analysis. Bull Earthq Eng 18:211-239. https://doi.org/10.1007/s10518-019-00722-0

Sorrentino L, Liberatore L, Decanini LD, Liberatore D (2014) The performance of churches in the 2012 Emilia earthquakes. Bull Earthq Eng. https://doi.org/10.1007/s10518-013-9519-3

Publisher's Note Springer Nature remains neutral with regard to jurisdictional claims in published maps and institutional affiliations. 